\title{
The Role of Systemic Antimicrobials in the Treatment of Endophthalmitis: A Review and an International Perspective
}

\author{
Andrzej Grzybowski • Magdalena Turczynowska • Stephen G. Schwartz • \\ Nidhi Relhan · Harry W. Flynn Jr.
}

Received: February 5, 2020 / Published online: July 1, 2020

(C) The Author(s) 2020

\begin{abstract}
Background: The optimal management of patients with endophthalmitis is challenging and includes both intravitreal and, in some cases, systemic antimicrobials. Systemic antimicrobials may be administered either intravenously or orally. In this article we review systemic antimicrobial options currently available for the treatment of types of endophthalmitis and the role of systemic antimicrobials (antibiotics and antifungals) in these treatments.
\end{abstract}

Digital Features To view digital features for this article go to https://doi.org/10.6084/m9.figshare.12424760.

A. Grzybowski

Department of Ophthalmology, University of

Warmia and Mazury, Olsztyn, Poland

A. Grzybowski

Institute for Research in Ophthalmology, Poznan, Poland

\section{Turczynowska}

Department of Ophthalmology, Stefan Żeromski

Specialist Municipal Hospital, Cracow, Poland

S. G. Schwartz · N. Relhan · H. W. Flynn Jr. ( $₫)$ Department of Ophthalmology, Bascom Palmer Eye Institute, University of Miami Miller School of

Medicine, Miami, FL, USA

e-mail: hflynn@med.miami.edu
Review: While systemic antimicrobials are not universally utilized in the management of endophthalmitis, they may be helpful in some circumstances. The blood-retinal barrier affects the penetration of systemic medications into the posterior segment of the eye differently; for example, moxifloxacin and imipenem cross the blood-retinal barrier relatively easily while vancomycin and amikacin do not. However, inflammation, including endophthalmitis, may disrupt the blood-retinal barrier, enhancing the penetration of systemic agents into the eye.

Conclusion: Systemic antimicrobials may be particularly beneficial in patients with certain types of endophthalmitis; as such, they are standard treatment in the management of endogenous endophthalmitis (fungal and bacterial) and also widely used for prophylaxis and treatment of open-globe injuries. Although systemic antimicrobials are used in some patients with acute-onset postoperative endophthalmitis following cataract surgery, the literature generally does not support this practice. It is noted that there are currently no randomized clinical trials demonstrating a benefit of systemic antibiotics for any category of endophthalmitis.

Keywords: Endogenous endophthalmitis; Endophthalmitis; Systemic antimicrobials; Systemic side-effects 


\section{Key Summary Points}

The optimal management of patients with endophthalmitis is challenging and includes both intravitreal and, in some cases, systemic antimicrobials.

This article reviews systemic antimicrobial options currently available for the treatment of different categories of endophthalmitis and the role of systemic antimicrobials (antibiotics and antifungals) in these treatments.

\section{INTRODUCTION}

Endophthalmitis is an uncommon but potentially devastating disease involving severe inflammation of intraocular tissues and fluids. This inflammatory condition is caused by either bacterial or fungal organisms. Although viruses and parasites may cause similar clinical presentations, these entities are not classically grouped within the traditional categories of endophthalmitis.

Endophthalmitis can be broadly classified as endogenous endophthalmitis or exogenous endophthalmitis. The former results from hematogenous spread from a systemic (nonocular) infectious source, also when the primary infectious source is never found. In contrast, exogenous endophthalmitis includes post-surgical, post-injection, and post-traumatic endophthalmitis and is associated with microbial keratitis. The causes include bacterial and fungal etiologies.

The optimal management of patients with endophthalmitis is challenging and includes both intravitreal and, in some cases, systemic antimicrobials [1]. Here, we review the role of systemic antimicrobials (intravenous vs. oral administration, and antibiotics vs. antifungals) for different categories of endophthalmitis.

\section{METHODS}

We searched the Cochrane Library and PubMed using pre-reported search terms and keywords in combination with both MeSH terms and text words. The search terms included ("endophthalmitis" [MeSH]) AND "systemic antibiotics" OR "systemic antimicrobials" OR "systemic antifungals"). The literature review was concluded 22 May 2020 and included randomized clinical controlled trials (RCTs), prospective and retrospective cohort studies, and case series published in English. All authors then selected the most relevant papers based on their expertise and combined clinical experience in the USA, Europe, and India. Finally, a narrative review was prepared based the authors' consensus opinion, with the ultimate aim to provide a balanced perspective.

This article is based on previously conducted studies and does not contain any studies with human participants or animals performed by any of the authors.

\section{COMMON ORGANISMS IN ENDOPHTHALMITIS}

In acute-onset postoperative endophthalmitis, the most common organisms are coagulasenegative Staphylococci, followed by Staphylococcus aureus and Streptococci. In India, fungal endophthalmitis is relatively more common (about 20\% of cases) than bacterial endophthalmitis. In delayed-onset (chronic) postoperative endophthalmitis, the most common organism is Propionobacterium acnes, followed by fungi. In early-onset bleb-associated endophthalmitis, the most common organisms are coagulase-negative Staphylococci and S. aureus. In delayed-onset bleb-associated endophthalmitis, the most common organisms are streptococci and Gram-negative organisms, including Moraxella catarrhalis. In endophthalmitis following intravitreal injection, the most common causal organisms are coagulasenegative Staphylococci, followed by Streptococci, Bacillus cereus, Enterococcus faecalis, and others. Overall, Streptococci and other oral flora are relatively more common in these patients than in 
postoperative patients. In post-traumatic endophthalmitis, the most common organisms are coagulase-negative Staphylococci, Streptococci, and Bacillus. In endogenous endophthalmitis, the most common organisms vary by geographic location, but overall fungi are more common than bacteria. Common fungal pathogens include Candida albicans and Aspergillus. In the USA and Europe, common bacterial pathogens include Gram-positive organisms, but in East Asia, Gram-negative organisms (including Klebsiella) predominate [2].

\section{SYSTEMIC ANTIMICROBIALS CURRENTLY AVAILABLE FOR THE TREATMENT OF ENDOPHTHALMITIS}

The blood-retinal barrier, which includes the retinal pigment epithelium and the walls of retinal capillaries with intercellular tight junctions, limits the penetration of systemic medications into the posterior segment of the eye [3]. In patients with intraocular inflammation, including endophthalmitis, breakdown of the blood-retinal barrier may allow the increased penetration of systemic agents, including antimicrobials [4], reinforcing the importance of understanding the characteristics of and differences between antibiotics.

\section{Glycopeptide antibiotics}

\section{Vancomycin}

Vancomycin is a glycopeptide antibiotic which acts by binding irreversibly to the D-alanyl-Dalanine moieties of the $N$-acetylmuramic acid and $\mathrm{N}$-acetylglucosamine peptides. This binding inhibits the synthesis and cross-linking of the $\mathrm{N}$-acetylmuramic acid. Vancomycin has broadspectrum coverage against Gram-positive organisms, including methicillin-resistant Staphylococcus aureus (MRSA), and is very effective when administered intravitreally, but penetration of the drug from the systemic cirulation into the posterior segment of the eye is poor. In a rabbit model, intravenous administration of vancomycin resulted in detectable amounts of drug in the aqueous, but not the vitreous, humor in both normal and inflamed eyes [5]. In another rabbit model, intravitreal vancomycin levels after systemic administration did not reach the minimum inhibitory concentration (MIC90) for Gram-positive organisms commonly causing intraocular infection even in those eyes with scleral or corneal perforating injury [6]. Systemic vancomycin must be administered intravenously (not orally) to have a therapeutic effect in patients with eye diseases. The risks associated with vancomycin include nephrotoxicity, "red man" syndrome, thrombocytopenia, neutropenia, fever, and dermatitis.

Alternative antibiotic options for the management of infections due to vancomycin-resistant organisms include linezolid, quinupristin/dalfopristin, daptomycin, and tigecycline, among others. There is limited published information on the intraocular penetration of these alternative drugs when used in systemic treatments [7].

\section{Cephalosporins}

Third-Generation (Ceftriaxone, Ceftazidime) and Fourth-Generation (Cefepime)

\section{Cephalosporins}

Third- and fourth-generation cephalosporins interrupt cell-wall synthesis via their affinity for penicillin-binding proteins (PBP). They have broad-spectrum coverage against Gram-negative organisms and show some activity against Gram-positive organisms, including methicillin-sensitive staphylococci, Streptococcus, Propionibacterium acnes, and others. In a rabbit model, ceftazidime was found not to penetrate into the vitreous humor after intravenous injection in noninflamed phakic and aphakic rabbit eyes, but there was effective penetration in inflamed rabbit eyes [8]. The vitreous levels of cefepime, a fourth-generation cephalosporin, after intravenous injections were reported to be above the MIC90 against Proteus mirabilis, Klebsiella species, Haemophilus influenzae, Streptococcus pneumoniae, S. pyogenes and Enterobacter species, but below the MIC90 against Staphylococcus aureus, S. epidermidis and 
Pseudomonas aeruginosa. Risks associated with ceftazidime include nausea, vomiting, diarrhea, and cross-allergy with other antibiotics.

\section{Beta-Lactams}

\section{Imipenem}

Systemic imipenem, a carbapenem beta-lactam antibiotic, shows good vitreous penetration into the posterior segment of the eye after intravenous infusion [9]. Carbapenems have a wide spectrum of antibacterial activity and are generally resistant to beta-lactamases. They are active against both Gram-positive and Gramnegative bacteria, including Propionobacterium acnes. Moreover, imipenem is reported to be nontoxic to ocular structures [10]. Despite these apparent advantages, imipenem is rarely used in the treatment of patients with endophthalmitis. Risks associated with imipenem include seizures and nephrotoxicity.

\section{Aminoglycosides}

\section{Amikacin}

Amikacin, an aminoglycoside antibiotic, has bactericidal activity against a broad spectrum of aerobic Gram-negative bacteria as well as activity against some Gram-positive bacterial species, but acquired resistance is a concern. Amikacin is poorly effective against enterococci and most anaerobic bacteria. Several studies have reported that intravenously administered aminoglycosides penetrate the blood-retinal barrier poorly and do not achieve therapeutic intraocular concentrations in the vitreous cavity [11, 12]. Risks associated with amikacin include nephrotoxicity, ototoxicity with deafness, and vertigo.

\section{Macrolides}

\section{Clarithromycin}

Clarithromycin, a semisynthetic macrolide antibiotic, has 50\% bioavailability and an antibiofilm action. It can be used as adjunctive therapy, but not as monotherapy, in patients with mycobacterial infections. In a case series of 19 patients with delayed-onset postoperative endophthalmitis caused by nontuberculous mycobacteria, systemic antibiotics were used for the management of 12 patients, with oral clarithromycin administered to seven of 12 patients for 1-4 weeks [13]. Risks associated with clarithromycin include cardiac toxicity, rhabdomyolysis, and renal failure.

\section{Fluoroquinolones}

Fluoroquinolones are bactericidal antibiotics that inhibit the bacterial enzymes DNA gyrase and topoisomerase IV, both of which are required for bacterial DNA replication, transcription, repair, and recombination. Fourthgeneration fluoroquinolones have a broad spectrum of coverage that includes both Grampositive and Gram-negative bacteria, many anaerobes, and obligate intracellular bacteria (chlamydia, mycoplasma, and some mycobacteria infections). However, fluoroquinolone resistance rates among coagulase-negative Staphylococcus endophthalmitis isolates have been reported to be as high as $40-60 \%$ [14]. Several studies have confirmed that fluoroquinolones administered orally (moxifloxacin and gatifloxacin) $[15,16]$, or even topically every $2 \mathrm{~h}$ (moxifloxacin), achieve adequate MIC in the aqueous and vitreous humor, respectively [17]. Additionally, the maximum intraocular levels are achieved in 1-2 days. Fluoroquinolones are generally well-tolerated, although systemic administration may cause serious side effects involving the tendons, muscles, joints, nerves, and central nervous system [18, 19]. However, a rapid development of ocular isolates showing fluoroquinolone resistance has been observed recently, which is concerning [20, 21]. Risks associated with fluoroquinolones include tendinopathy, dysglycemia, thrombocytopenia, and cardiac toxicity.

\section{Antibiotic Combinations}

\section{Trimethoprim-Sulfamethoxazole}

Trimethoprim-sulfamethoxazole is a combination antibiotic formulation that is commonly used as an oral antibiotic. Its action includes blocking microbial folic acid synthesis [22]. This agent does achieve therapeutic levels in the vitreous 
following oral administration [1]. Oral administration of trimethoprim-sulfamethoxazole as adjunctive therapy has been reported in the treatment of endogenous endophthalmitis with subretinal abscess due to Nocardia [23, 24], MRSA [25], and other organisms. Risks associated with trimethoprim-sulfamethoxazole include nausea, vomiting, peripheral neuritis, Stevens-Johnson syndrome, and toxic epidermal necrolysis.

\section{Antifungals}

\section{Amphotericin B}

Amphotericin B is a member of the polyene class of antifungal drugs which bind with ergosterol, a component of fungal cell membranes, forming pores that cause rapid leakage of intracellular material and subsequent fungal cell death. Amphotericin B administered intravenously seems to work efficiently in patients with Candida endophthalmitis, but due to its propensity to cause systemic toxicity, it generally should be used under the supervision of an internal medicine or infectious disease specialist. Close monitoring is necessary, as the risks associated with amphotericin B include fever, chills, renal toxicity, electrolyte imbalances, cardiac arrythmias, and hepatotoxicity.

\section{Voriconazole}

Voriconazole is a member of the azole class of antifungal drugs that causes inhibition of cytochrome P450-dependent 14a-lanosterol demethylation, which is a vital step in cell membrane ergosterol synthesis by fungi. Voriconazole was first introduced in 2002 and shows good oral bioavailability and intraocular penetration. Its use has been increasing more recently, and it may have a broader spectrum of coverage against various fungi (filamentous as well as yeast) than originally thought $[26,27]$. Similar to systemic amphotericin $\mathrm{B}$, patients receiving voriconazole require close monitoring because risks associated with voriconazole include hepatic toxicity, cardiac arrythmias, fever, and hypertension.

\section{Caspofungin}

Caspofungin is a lipopeptide antifungal that belongs to the echinocandin class of antifungal drugs. Intravitreal caspofungin has been reported to be helpful in the management of fungal endophthalmitis $[28,29]$. Systemic caspofungin also has been reported to be successful in the treatment of endogenous candidal endophthalmitis [30, 31]. However, other investigators have reported systemic caspofungin to be ineffective as monotherapy [32]. Risks associated with caspofungin include hepatotoxicity, Stevens-Johnson syndrome, and toxic epidermal necrolysis.

\section{ROLE OF SYSTEMIC ANTIMICROBIALS (ANTIBIOTICS AND ANTIFUNGALS) IN THE MANAGEMENT OF DIFFERENT ETIOLOGIES OF ENDOPHTHALMITIS}

Systemic antimicrobials are useful in the management of endophthalmitis due to certain etiologies (Table 1). In this section we discuss their role in different categories of endophthalmitis. Although the use of adjunctive systemic antibiotics would seem to be beneficial in patients with endophthalmitis, the empirical findings do not support their use in most categories of infection, possibly related to the concentration of antibiotics achieved inside the eye. In general, much higher doses may be achieved with intravitreal, rather than systemic, administration, and the effectiveness of antibiotics may greatly increase with increasing doses.

Further, the systemic administration of antimicrobials is associated with systemic toxicities; in contrast, the intravitreal administration of antimicrobials is associated only with ocular toxicities. Perhaps the most potentially toxic agents are vancomycin and the aminoglycosides; fortunately, these agents are easy to obtain for intravitreal use.

\section{Endophthalmitis After Open-Globe Injuries}

Early wound closure and prophylactic use of systemic levofloxacin was associated with a very low endophthalmitis risk in a large series of 
Table 1 Role of systemic antimicrobials (antibiotics and antifungals) in the management of different etiologies of endophthalmitis

\begin{tabular}{|c|c|}
\hline $\begin{array}{l}\text { Type of } \\
\text { endophthalmitis }\end{array}$ & $\begin{array}{l}\text { Role of systemic } \\
\text { antimicrobials }\end{array}$ \\
\hline $\begin{array}{l}\text { Endophthalmitis after } \\
\text { open-globe injuries }\end{array}$ & $\begin{array}{l}\text { Usually given for } \\
\text { endophthalmitis prophylaxis } \\
\text { or treatment }\end{array}$ \\
\hline $\begin{array}{l}\text { Endogenous fungal } \\
\text { endophthalmitis }\end{array}$ & Yes (antifungals) \\
\hline $\begin{array}{l}\text { Endogenous bacterial } \\
\text { endophthalmitis }\end{array}$ & Yes (antibiotics) \\
\hline $\begin{array}{l}\text { Post-cataract surgery } \\
\text { endophthalmitis }\end{array}$ & $\begin{array}{l}\text { Rarely in USA but frequently } \\
\text { in other countries }\end{array}$ \\
\hline $\begin{array}{l}\text { Post-intravitreal } \\
\text { injection } \\
\text { endophthalmitis }\end{array}$ & $\begin{array}{l}\text { Rarely in USA but more } \\
\text { frequently in other countries }\end{array}$ \\
\hline $\begin{array}{l}\text { Filtering bleb-associated } \\
\text { endophthalmitis }\end{array}$ & $\begin{array}{l}\text { Rarely in USA but more } \\
\text { frequently in other countries }\end{array}$ \\
\hline $\begin{array}{l}\text { Post-keratitis } \\
\text { endophthalmitis }\end{array}$ & $\begin{array}{l}\text { Rarely in USA but more } \\
\text { frequently in other countries }\end{array}$ \\
\hline
\end{tabular}

patients with open-globe injuries without endophthalmitis at initial presentation [33]. Prophylactic systemic antibiotics are often utilized in such cases with open-globe injuries, although no results from randomized clinical trials are available that support their use in this situation. The use of systemic antimicrobials in this situation is consistent with the widespread use of systemic antibiotics in patients with penetrating injuries to other body parts.

Pars plana vitrectomy (PPV) with the injection of intravitreal antibiotics is a standard treatment for the management of established post-traumatic endophthalmitis. The benefits of systemic antimicrobials in these patients are unknown.

\section{Endogenous Fungal Endophthalmitis}

In patients with endogenous fungal endophthalmitis, systemic antifungals (amphotericin B or voriconazole) are generally used in consultation with an infectious disease or internal medicine specialist. The underlying rationale is that patients with endogenous endophthalmitis have, by definition, a systemic (non-ocular) source of infection, even if that source is never found. Systemic antifungals are beneficial not only in the treatment of the ocular infection but also in the treatment of the widespread infection throughout the body or other organ systems. In addition, intravitreal antifungal agents are usually employed and PPV can be considered [34-36].

\section{Endogenous Bacterial Endophthalmitis}

In patients with endogenous bacterial endophthalmitis, systemic antibiotics are necessary and are generally used in consultation with an internist. Again, these patients by definition have a systemic (non-ocular) source of infection, even if it cannot be identified. In some patients with severe intraocular infection, adjunctive PPV can be considered [36-38]. As an illustration of the effectiveness of systemic antibiotics in this condition, in a series of 40 eyes (35 patients) with endogenous endophthalmitis from the University of Florida, the authors reported positive intraocular cultures in $28.6 \%$ of patients before initiation of treatment with systemic antibiotics and in $0 \%$ after initiation [39].

\section{Post-Cataract Surgery Endophthalmitis}

The Endophthalmitis Vitrectomy Study (EVS) was a large randomized clinical trial conducted in the early 1990s that evaluated the role of early PPV and systemic antibiotic treatment in the management of acute-onset postoperative endophthalmitis following cataract surgery or secondary intraocular lens (IOL) implantation [40]. The authors of this study reported no significant difference in visual acuity outcomes and complication rates with or without systemic antibiotics (intravenous ceftazidime and amikacin). These two agents have limited effectiveness against coagulase-negative staphylococci, which was responsible for $80 \%$ of 
culture-positive cases in the EVS. Many newer antimicrobials, including fourth-generation fluoroquinolones (gatifloxacin or moxifloxacin), have been reported to achieve therapeutic levels of intravitreal drug with systemic use, but there is currently relatively little evidence to support their use in modern clinical practice. As per the EVS, systemic antibiotics may be considered in selected patients with more severe signs and symptoms, such as panophthalmitis, presenting visual acuity of light perception or large hypopyon or lack of red reflex.

Systemic antibiotics appear to be used more commonly in Europe than in the USA for these patients. The European Society of Cataract and Refractive Surgeons (ESCRS) published consensus guidelines in 2013 which recommend-for patients with severe acute-onset postoperative endophthalmitis for which the treating physician is considering systemic antibiotics-using the same antibiotics as those given intravitreally (i.e., vancomycin and ceftazidime rather than amikacin and ceftazidime). These guidelines also recommend clarithromycin taken orally and possibly additional moxifloxacin taken orally in patients with chronic (delayed-onset) postoperative endophthalmitis following cataract surgery [41]. More recently, the European Vitreo-Retinal Society reported a retrospective series of 237 eyes with acute endophthalmitis following intraocular surgery or intravitreal injections. Of this group, the majority (153 eyes, 64.6\%) had undergone cataract surgery or secondary lens implantation. The investigators reported the use of systemic antibiotics in $66.6 \%$ of eyes [42].

\section{Post-Intravitreal Injection Endophthalmitis}

The treatment includes vitreous tap or PPV with intravitreal antimicrobials. Systemic antimicrobials are generally not used for the management of post-intravitreal injection endophthalmitis, either in Europe or in the USA $[43,44]$.

\section{Filtering Bleb-Associated Endophthalmitis}

The treatment is similar to the management of post-intravitreal injection endophthalmitis and includes vitreous tap or PPV with intravitreal antimicrobials. Systemic antimicrobials are generally not used for the management of filtering bleb-associated endophthalmitis [45-49].

\section{Post-Keratitis Endophthalmitis}

Treatment of post-keratitis endophthalmitis includes corneal scraping or biopsy which may be followed by therapeutic keratoplasty in addition to the pars plana vitrectomy and injection of intravitreal antimicrobials (antibiotics or antifungals). Frequent applications of topical antimicrobials are utilized in the followup course. Systemic antimicrobials are generally not utilized for the management of post-keratitis endophthalmitis [50-53].

\section{COMPLICATIONS AND SIDE- EFFECTS OF SYSTEMIC ANTIMICROBIALS}

Knowledge of the potential side-effects and complications of administering systemic antimicrobials is very important (Table 2) [54]. The role of an infectious disease consultant or internist is invaluable in those cases requiring multi-specialty care. 


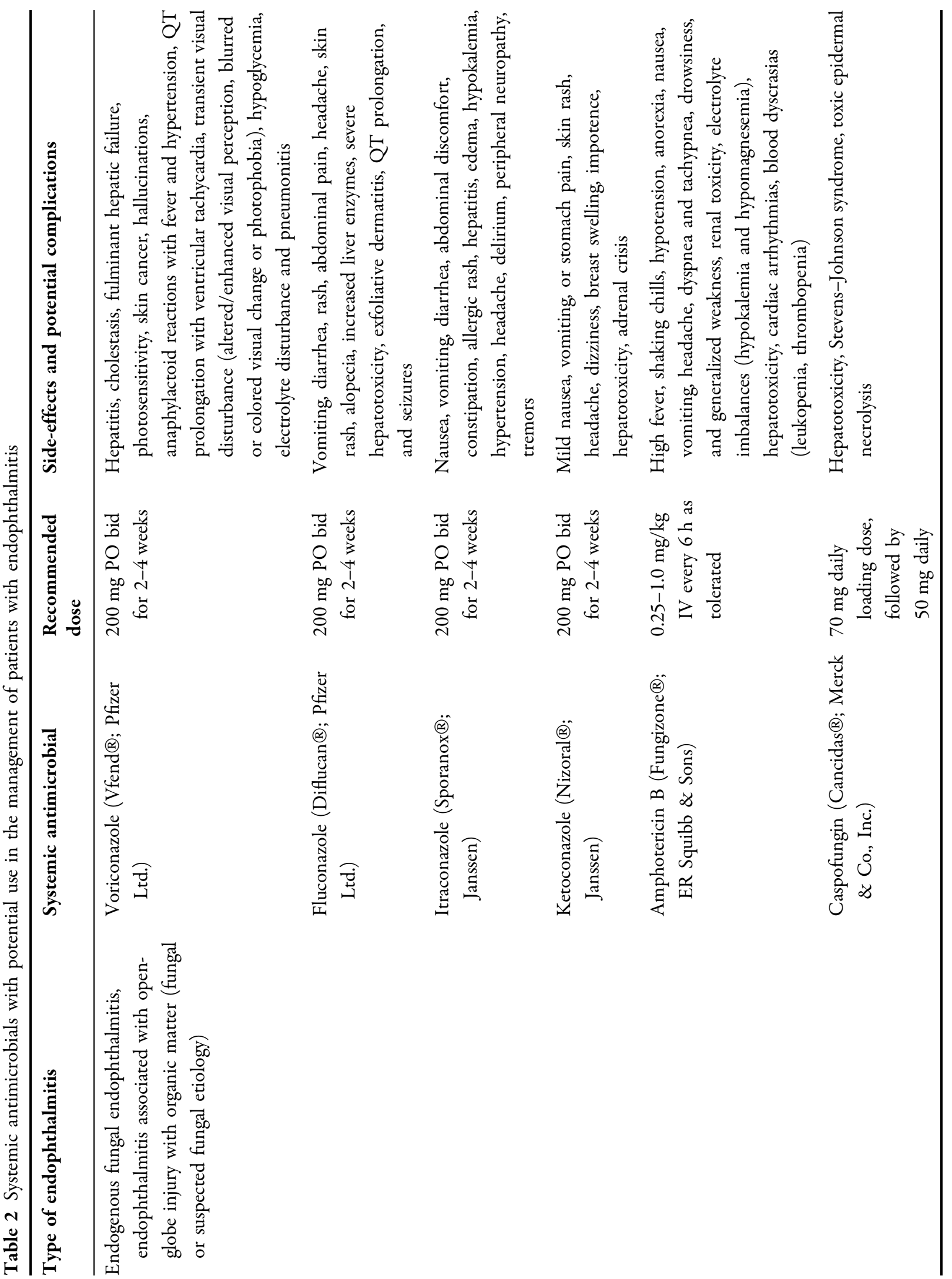




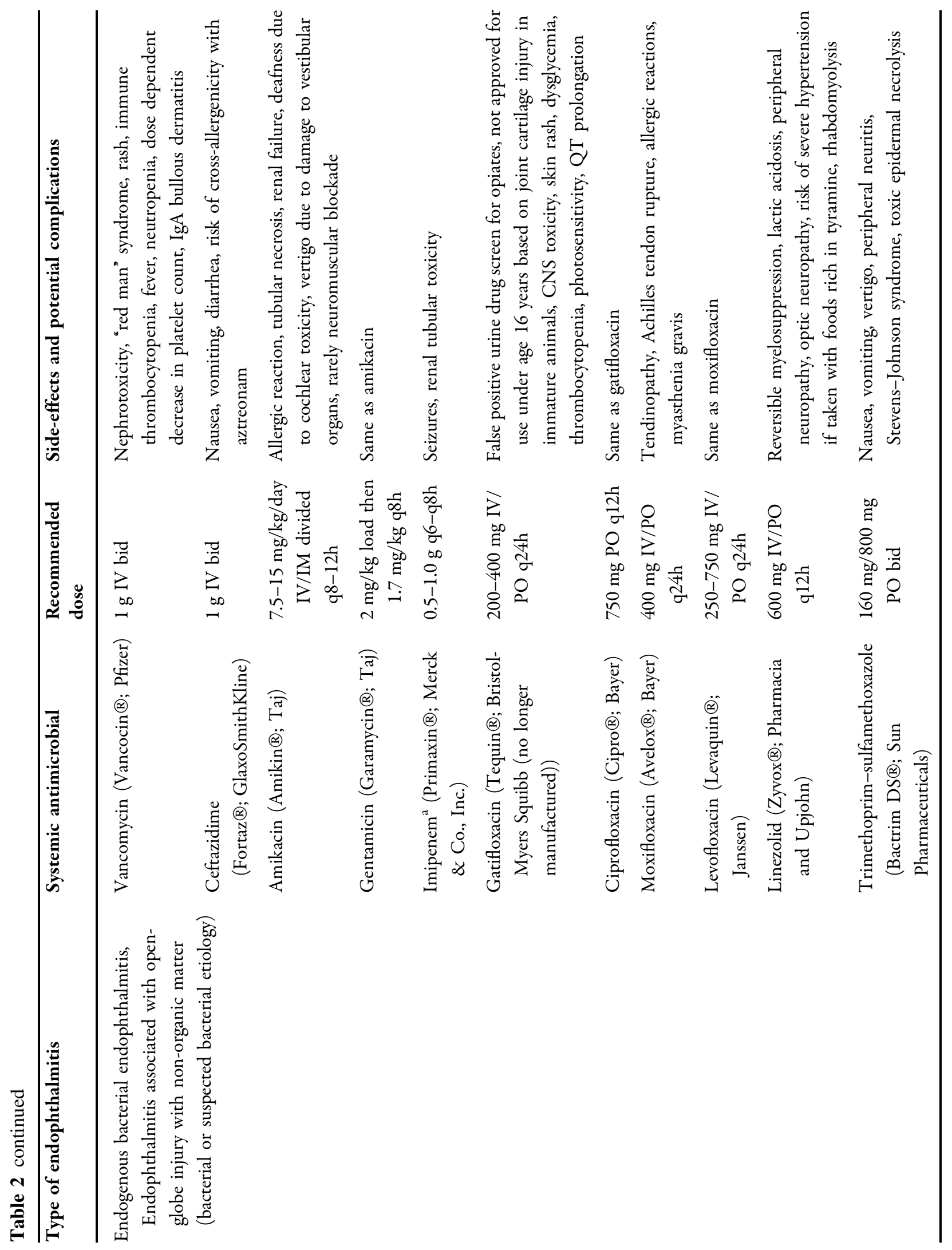




\section{CONCLUSIONS}

We have reviewed the current usage of systemic antimicrobials in different types of endophthalmitis. Our combined clinical experience in the field encompasses clinical practice in the USA, Europe, and India, and we have attempted to provide a consensus opinion. There is considerable uncertainty on this topic because, other than the EVS, there is no evidence from relevant randomized clinical trials to provide guidance. The EVS reported that ceftazidime and amikacin had no benefit in the treatment of acute-onset postoperative endophthalmitis following cataract surgery or secondary IOL implantation. Therefore, in our review, we have used a consensus approach based on lowerquality evidence.

Systemic antimicrobials are considered to be beneficial in the management of endogenous (fungal and bacterial) endophthalmitis and as endophthalmitis prophylaxis in open-globe injury. The benefits of systemic antimicrobials for any other category of endophthalmitis (especially following cataract surgery) are generally not supported by the literature. Certain patients with severe disease may benefit on a case-by-case basis, but the increased costs of systemic agents and possible related systemic toxicity remain important considerations. Consultation with an infectious disease specialist or internist when the initiation of systemic antimicrobial agents is being considered is important, as is the subsequent monitoring for possible systemic side effects.

It is possible that there is a potential role for some systemic antimicrobials, especially in patients with severe or nonresponsive disease. For example, imipenem has activity against many bacterial species and is relatively nontoxic to the eye. Further investigation of this agent would appear warranted. Further, continued systemic antibiotics are easier to administer than repeated intravitreal injections. Achieving sufficient and sustained intraocular therapeutic levels of drug is essential for the effective management of endophthalmitis. Currently, the most effective way to achieve 
therapeutic drug levels in the vitreous humor is by way of intravitreal administration.

\section{ACKNOWLEDGEMENTS}

Funding. This study was supported by the NIH Center Core Grant P30EY014801, an unrestricted grant to the University of Miami from the National Eye Institute, and a grant from the Research to Prevent Blindness. No funding or sponsorship was received for the publication of this article.

Authorship. All named authors meet the International Committee of Medical Journal Editors (ICMJE) criteria for authorship for this article, take responsibility for the integrity of the work as a whole, and have given their approval for this version to be published.

Authorship Contributions. All authors contributed to initial draft and revisions. All coauthors agree with the final version.

Disclosures. Andrzej Grzybowski, Magdalena Turczynowska, Stephen G. Schwartz, Nidhi Relhan and Harry W. Flynn, Jr. declare that they have no competing interests in this section. Andrzej Grzybowski is a member of the journal's Editorial Board.

Compliance with Ethics Guidelines. This article is based on previously published studies and does not include any ongoing clinical studies with human participants or animals performed by the authors.

Open Access. This article is licensed under a Creative Commons Attribution-NonCommercial 4.0 International License, which permits any non-commercial use, sharing, adaptation, distribution and reproduction in any medium or format, as long as you give appropriate credit to the original author(s) and the source, provide a link to the Creative Commons licence, and indicate if changes were made. The images or other third party material in this article are included in the article's Creative Commons licence, unless indicated otherwise in a credit line to the material. If material is not included in the article's Creative Commons licence and your intended use is not permitted by statutory regulation or exceeds the permitted use, you will need to obtain permission directly from the copyright holder. To view a copy of this licence, visit http://creativecommons.org/licenses/by$\mathrm{nc} / 4.0 /$.

\section{REFERENCES}

1. Brockhaus L, Goldblum D, Eggenschwiler L, et al. Revisiting systemic treatment of bacterial endophthalmitis: a review of intravitreal penetration of systemic antibiotics. Clin Microbiol Infect. 2019;25: 1364-9. https://doi.org/10.1016/j.cmi.2019.01.017.

2. Vaziri K, Schwartz SG, Kishor K, et al. Endophthalmitis: state of the art. Clin Ophthalmol. 2015;9: 95-108. https://doi.org/10.2147/opth.s76406.

3. Urtti A. Challenges and obstacles of ocular pharmacokinetics and drug delivery. Adv Drug Deliv Rev. 2006;58:1131-5. https://doi.org/10.1016/j. addr.2006.07.027.

4. Occhiutto ML, Freitas FR, Maranhao RC, et al. Breakdown of the blood-ocular barrier as a strategy for the systemic use of nanosystems. Pharmaceutics. 2012;4:252-75. https://doi.org/10.3390/ pharmaceutics 4020252 .

5. Pryor JG, Apt L, Leopold IH. Intraocular penetration of vancomycin. Arch Ophthalmol. 1962;67:608-11.

6. Ahmed S, Kuruvilla O, Yee DC, et al. Intraocular penetration of systemic antibiotics in eyes with penetrating ocular injury. J Ocul Pharmacol Ther. 2014;30:823-30. https://doi.org/10.1089/jop.2014. 0056.

7. Relhan N, Albini TA, Pathengay A, et al. Endophthalmitis caused by gram-positive organisms with reduced vancomycin susceptibility: literature review and options for treatment. Br J Ophthalmol. 2016;100:446-52. https://doi.org/10.1136/ bjophthalmol-2015-307722.

8. Aguilar HE, Meredith TA, Shaarawy A, et al. Vitreous cavity penetration of ceftazidime after intravenous administration. Retina. 1995;15:154-9.

9. Adenis JP, Mounier M, Salomon JL, et al. Human vitreous penetration of imipenem. Eur J Ophthalmol. 1994;4:115-7. 
10. Derick RJ, Paylor R, Peyman GA. Toxicity of imipenem in vitreous replacement fluid. Ann Ophthalmol. 1987;19:338-9.

11. El-Massry A, Meredith TA, Aguilar HE, et al. Aminoglycoside levels in the rabbit vitreous cavity after intravenous administration. Am J Ophthalmol. 1996;122:684-9.

12. Mandell BA, Meredith TA, Aguilar E, et al. Effects of inflammation and surgery on amikacin levels in the vitreous cavity. Am J Ophthalmol. 1993;115:770-4.

13. Shah M, Relhan N, Kuriyan AE, et al. Endophthalmitis caused by non-tuberculous Mycobacterium: clinical features, antimicrobial susceptibilities and treatment outcomes. Am J Ophthalmol. 2016. https://doi.org/10.1016/j.ajo. 2016.03.035.

14. Schimel AM, Miller D, Flynn HW Jr. Endophthalmitis isolates and antibiotic susceptibilities: a 10-year review of culture-proven cases. Am J Ophthalmol. 2013;156(50-52):e51. https://doi.org/10. 1016/j.ajo.2013.01.027.

15. Hariprasad SM, Mieler WF, Holz ER. Vitreous and aqueous penetration of orally administered gatifloxacin in humans. Arch Ophthalmol. 2003;121: 345-50.

16. Hariprasad SM, Shah GK, Mieler WF, et al. Vitreous and aqueous penetration of orally administered moxifloxacin in humans. Arch Ophthalmol. 2006;124:178-82. archopht.124.2.178.

17. Hariprasad SM, Blinder KJ, Shah GK, et al. Penetration pharmacokinetics of topically administered $0.5 \%$ moxifloxacin ophthalmic solution in human aqueous and vitreous. Arch Ophthalmol. 2005;123: 39-44. https://doi.org/10.1001/archopht.123.1.39.

18. Aydin E, Kazi AA, Peyman GA, et al. Intravitreal toxicity of moxifloxacin. Retina. 2006;26:187-90. https://doi.org/10.1097/00006982-20060200000011.

19. Kazi AA, Jermak CM, Peyman GA, et al. Intravitreal toxicity of levofloxacin and gatifloxacin. Ophthalmic Surg Lasers Imaging. 2006;37:224-9.

20. Relhan N, Pathengay A, Schwartz SG, et al. Emerging worldwide antimicrobial resistance, antibiotic stewardship and alternative intravitreal agents for the treatment of endophthalmitis. Retina. 2017;37(5):811-18. https://doi.org/10.1097/iae. 0000000000001603.

21. Stringham JD, Relhan N, Miller D, et al. Trends in fluoroquinolone nonsusceptibility among coagulase-negative staphylococcus isolates causing endophthalmitis, 1995-2016. JAMA Ophthalmol. 2017;135(7):814-5. https://doi.org/10.1001/ jamaophthalmol.2017.1826.

22. Smilack JD. Trimethoprim-sulfamethoxazole. Mayo Clin Proc. 1999;74:730-4. https://doi.org/10. 4065/74.7.730.

23. $\mathrm{Xu} \mathrm{H}, \mathrm{Fu} \mathrm{B}, \mathrm{Xu} \mathrm{L}$, et al. Disseminated nocardiosis with subretinal abscess in a patient with nephrotic syndrome-a case report. BMC Ophthalmol. 2018;18:234. https://doi.org/10.1186/s12886-0180883-2.

24. Nakamura I, Nagakura T, Fujita H, et al. Nocardia elegans infection: a case report and literature review. Int J Infect Dis. 2017;54:15-7. https://doi.org/10. 1016/j.ijid.2016.10.031.

25. Fortun J, Modi YS, Bessette A, et al. Clinical features and management of subretinal abscesses secondary to methicillin-resistant Staphylococcus aureus endogenous endophthalmitis. Ophthalmic Surg Lasers Imaging Retina. 2017;48:134-42. https://doi. org/10.3928/23258160-20170130-07.

26. Maschmeyer G, Haas A. Voriconazole: a broad spectrum triazole for the treatment of serious and invasive fungal infections. Future Microbiol. 2006;1:365-85. https://doi.org/10.2217/17460913. 1.4.365.

27. Sridhar J, Kuriyan AE, Flynn HW Jr, et al. Endophthalmitis caused by pseudomonas aeruginosa: clinical features, antibiotic susceptibilities, and treatment outcomes. Retina. 2015;35:1101-6. https://doi.org/10.1097/iae.0000000000000469.

28. Danielescu C, Cantemir A, Chiselita D. Successful treatment of fungal endophthalmitis using intravitreal caspofungin. Arq Bras Oftalmol. 2017;80: 196-8. 20170048.

29. Yadav HM, Thomas B, Thampy C, et al. Management of a case of Candida albicans endogenous endophthalmitis with intravitreal caspofungin. Indian J Ophthalmol. 2017;65:529-31. https://doi. org/10.4103/ijo.IJO_781_16.

30. Sarria JC, Bradley JC, Habash R, et al. Candida glabrata endophthalmitis treated successfully with caspofungin. Clin Infect Dis. 2005;40:e46-48. https://doi.org/10.1086/427753.

31. Contreras I, Arruabarrena C, Figueroa MS. Treatment of bilateral candidal endophthalmitis with intravenous caspofungin. Retin Cases Brief Rep. 2007;1:175-7. https://doi.org/10.1097/01.ICB. 0000279654.16358 .00 . 
32. Gauthier GM, Nork TM, Prince R, et al. Subtherapeutic ocular penetration of caspofungin and associated treatment failure in Candida albicans endophthalmitis. Clin Infect Dis. 2005;41:e27-28. https://doi.org/10.1086/431761.

33. Colyer MH, Weber ED, Weichel ED, et al. Delayed intraocular foreign body removal without endophthalmitis during operations Iraqi freedom and enduring freedom. Ophthalmology. 2007;114: 1439-47. https://doi.org/10.1016/j.ophtha.2006. 10.052 .

34. Sridhar J, Flynn HW Jr, Kuriyan AE, et al. Endogenous fungal endophthalmitis: risk factors, clinical features, and treatment outcomes in mold and yeast infections. J Ophthalmic Inflamm Infect. 2013;3:60. https://doi.org/10.1186/1869-5760-360.

35. Lingappan A, Wykoff CC, Albini TA, et al. Endogenous fungal endophthalmitis: causative organisms, management strategies, and visual acuity outcomes. Am J Ophthalmol. 2012;153(162-166):e161. https://doi.org/10.1016/j. ajo.2011.06.020.

36. Flynn HW. The clinical challenge of endogenous endophthalmitis. Retina. 2001;21:572-4. https:// doi.org/10.1097/00006982-200112000-00002.

37. Okada AA, Johnson RP, Liles WC, et al. Endogenous bacterial endophthalmitis. Report of a ten-year retrospective study. Ophthalmology. 1994;101: 832-8.

38. Wong J. Endogenous bacterial endophthalmitis: an east Asian experience and a reappraisal of a severe ocular affliction. Ophthalmology. 2000;107: 1483-91. 6420(00)00216-5.

39. Regan KA, Radhakrishnan NS, Hammer JD, et al. Endogenous endophthalmitis: yield of the diagnostic evaluation. BMC Ophthalmol. 2020;20:138. https://doi.org/10.1186/s12886-020-01418-9.

40. [No authors listed]. Results of the Endophthalmitis Vitrectomy Study. A randomized trial of immediate vitrectomy and of intravenous antibiotics for the treatment of postoperative bacterial endophthalmitis. Endophthalmitis Vitrectomy Study Group. Arch Ophthalmol. 1995;113:1479-96. https://doi.org/10.1001/archopht.1995. 01100120009001.

41. Lundstrom M, Barry P, Henry Y, et al. Evidencebased guidelines for cataract surgery: guidelines based on data in the European Registry of Quality Outcomes for Cataract and Refractive Surgery database. J Cataract Refract Surg. 2012;38:1086-93. https://doi.org/10.1016/j.jcrs.2012.03.006.
42. Soliman MK, Gini G, Kuhn F, et al. International practice patterns for the management of acute postsurgical and postintravitreal injection endophthalmitis: European Vitreo-Retinal Society endophthalmitis study report 1. Ophthalmol Retina. 2019;3:461-7. https://doi.org/10.1016/j. oret.2019.03.009.

43. Chiang A, Kaiser RS, Avery RL, et al. Endophthalmitis in microincision vitrectomy: outcomes of gas-filled eyes. Retina. 2011;31:1513-7. https://doi. org/10.1097/IAE.0b013e3182209290.

44. Dave VP, Pathengay A, Schwartz SG, et al. Endophthalmitis following pars plana vitrectomy: a literature review of incidence, causative organisms, and treatment outcomes. Clin Ophthalmol. 2014;8: 2183-8. https://doi.org/10.2147/opth.s71293.

45. Katz LJ, Cantor LB, Spaeth GL. Complications of surgery in glaucoma. Early and late bacterial endophthalmitis following glaucoma filtering surgery. Ophthalmology. 1985;92:959-63. https://doi. org/10.1016/s0161-6420(85)33948-9.

46. Leng T, Miller D, Flynn HW Jr, et al. Delayed-onset bleb-associated endophthalmitis (1996-2008): causative organisms and visual acuity outcomes. Retina. 2011;31:344-52. https://doi.org/10.1097/ IAE.0b013e3181e09810.

47. Song A, Scott IU, Flynn HW Jr, et al. Delayed-onset bleb-associated endophthalmitis: clinical features and visual acuity outcomes. Ophthalmology. 2002;109:985-91. https://doi.org/10.1016/s01616420(02)00965-X.

48. Vaziri K, Kishor K, Schwartz SG, et al. Incidence of bleb-associated endophthalmitis in the United States. Clin Ophthalmol. 2015;9:317-22. https:// doi.org/10.2147/OPTH.S75286.

49. Busbee BG, Recchia FM, Kaiser R, et al. Bleb-associated endophthalmitis: clinical characteristics and visual outcomes. Ophthalmology. 2004;111: 1495-503. https://doi.org/10.1016/j.ophtha.2004. 01.028 (discussion 1503).

50. Scott IU, Flynn HW Jr, Feuer W, et al. Endophthalmitis associated with microbial keratitis. Ophthalmology. 1996;103:1864-70. https://doi.org/10. 1016/s0161-6420(96)30415-6.

51. Rosenberg KD, Flynn HW Jr, Alfonso EC, et al. Fusarium endophthalmitis following keratitis associated with contact lenses. Ophthalmic Surg Lasers Imaging. 2006;37:310-3.

52. Henry CR, Flynn HW Jr, Miller D, et al. Infectious keratitis progressing to endophthalmitis: a 15-year study of microbiology, associated factors, and 
clinical outcomes. Ophthalmology. 2012;119:

2443-9. https://doi.org/10.1016/j.ophtha.2012.06. 030.

53. Henry CR, Flynn HW Jr, Miller D, et al. Delayedonset endophthalmitis associated with corneal suture infections. J Ophthalmic Inflamm Infect. 2013;3:51. https://doi.org/10.1186/1869-5760-351.
54. Gilbert DN, Chambers HF, Eliopoulos GM, et al (eds). The Sanford guide to antimicrobial therapy 2019 (pocket edition). 2019. Sperryville: Antimicrobial Therapy Inc. 